\title{
O financiamento da educação especial no âmbito dos fundos da educação básica: Fundef e Fundeb
}

\section{Special education funding in the sphere of Fundef and Fundeb as basic education funds}

\author{
Marileide Gonçalves França ${ }^{1}$
}

\begin{abstract}
RESUMO
Este trabalho objetiva analisar a educação especial no contexto do financiamento da educação por meio da análise dos efeitos do Fundef e do Fundeb para o atendimento das pessoas com deficiência, transtornos globais de desenvolvimento e altas habilidades/superdotação, no período de 2007 a 2013, no que tange ao número de matrículas no Estado do Espírito Santo e os valores mínimos por aluno da educação especial estabelecidos a nível nacional, e no Espírito Santo, para essa modalidade de ensino. Os resultados apontam que as políticas de financiamento e de educação especial, desenvolvidas pelo governo federal, têm repercutido na incorporação das matrículas dessa modalidade de ensino nos sistemas educacionais brasileiros, porém, isso não minimiza a ausência de condições mínimas de qualidade da rede pública de ensino para o atendimento a essa população que historicamente foi excluída do processo de escolarização. Desse modo, há a necessidade de discutir acerca dos recursos financeiros voltados a essa modalidade de ensino, a (re)definição dos critérios de ponderação, a contagem de matrículas da rede privada de ensino para recebimento de recursos públicos, a articulação dos entes federados e, principalmente, o aumento da participação da União, na busca pela universalização do atendimento ao público da educação especial.

Palavras-chave: educação especial; financiamento da educação; política pública.
\end{abstract}

DOI: $10.1590 / 0104-4060.42415$

1 Instituto Federal do Espírito Santo. Cariacica, Espírito Santo, Brasil. Campus Cariacica. Rodovia Governador José Sette, s/n. CEP: 29150-410.E-mail: leidemary8@yahoo.com.br 


\begin{abstract}
This study aims at analyzing special education in the context of education funding. It assessed the effects of Fundef and Fundeb on services provided to people with disabilities, pervasive developmental disorder and high-potential/gift, between 2007 and 2013. The study took into account the number of enrollments in the State of Espírito Santo, Brazil, and the minimum amounts per special education student set at national and state levels for this modality of education. The results show that the special education funding policies developed by the federal government have resulted in the incorporation of special education enrollment into Brazilian education systems. However, this does not minimize the lack of minimal quality conditions in the public school network for serving this population, who was historically excluded from the schooling process. Thus, it is necessary to discuss the financial resources intended for this education modality; the (re)definition of the deliberation criteria; the number of enrollments in the private school network to receive public resources; the interaction between states and, especially, the participation of the Federal Government towards universalizing public service for special education.
\end{abstract}

Keywords: special education; education funding; public policy.

\title{
Introdução
}

A educação especial como política pública, isto é, "como forma de intervenção estatal na oferta e proteção de determinado direito de cidadania" (CURY, 2007, p. 832) pressupõe investimento financeiro por parte do Poder Público para garantir a sua concretização e oferecer serviços públicos voltados ao atendimento das pessoas com deficiência, transtornos globais de desenvolvimento (TGD) e altas habilidades/superdotação. Nessa direção, ela integra o sistema de financiamento da educação no Brasil. No entanto, a sua configuração, enquanto política pública, constitui um processo recente na sociedade brasileira. (MAZZOTTA, 2011).

O financiamento da educação na Constituição Federal de 1988 (CF/88) caracterizou-se pela orientação da descentralização financeira, representando o aumento da participação dos estados e municípios na arrecadação tributária e receitas disponíveis. No que se refere à educação especial, a $\mathrm{CF} / 88$ estabelece, no art. 208, inciso III, o "atendimento educacional especializado aos portadores de deficiência, preferencialmente na rede regular de ensino". (BRASIL, 1988). Cabe ressaltar, no âmbito dessa Constituição, no art. 213, a proposição de que sejam 
destinados recursos públicos às entidades da sociedade civil para atendimento às pessoas com deficiência, TGD e altas habilidades/superdotação. Segundo Kassar (2011), os serviços assistenciais, educacionais e de promoção à saúde oferecidos foram predominantemente assumidos pelas instituições privadas, organizações não governamentais e/ou sociedade civil. Entretanto, essa trajetória histórica também apresenta peculiaridades, na medida em que observamos a presença tímida do Poder Público em relação à garantia dos direitos de acesso e permanência das pessoas com deficiência, TGD e altas habilidades/superdotação nos sistemas públicos de educação.

Na década de 1990 observamos profundas mudanças nas políticas educacionais, como a aprovação da Lei de Diretrizes e Bases da Educação de 1996 (LDB/96), e na organização do financiamento da educação, com a implantação de fundos específicos voltados à manutenção e desenvolvimento do ensino. $\mathrm{Na}$ LDB/96 foi estabelecido o dever do Estado com a educação mediante a garantia de "padrões mínimos de qualidade de ensino, definido como a variedade e quantidade mínimas, por aluno, de insumos indispensáveis ao desenvolvimento do processo de ensino-aprendizagem". (BRASIL, 1996, art. 4º inciso IX). Essa ideia articula-se à necessidade de investir esforços no intuito de garantir a oferta e melhores condições de ensino.

Nessa direção, a educação foi ratificada como tarefa compartilhada entre União, Distrito Federal, estados e municípios, sendo organizada sob a forma de regime de colaboração (CF/88, art. 211 e LDB/96, art. $\left.8^{\circ}\right)$. Cada instância é responsável pela administração, expansão e manutenção dos seus respectivos sistemas de ensino, incluindo a organização de políticas e programas voltados à educação especial. No âmbito dessa Lei ainda foi enfatizado o papel coordenador e articulador da União em relação aos demais entes federados (LDB/96, art. $8^{\circ}$ ), tendo como uma das suas tarefas a responsabilidade pela educação de alunos com deficiência, TGD e altas habilidades/superdotação.

A educação especial, nesse cenário, apresentou avanços em termos de legislação e também sofreu implicações na sua organização e financiamento. A LDB/96, ao estabelecer a educação especial como modalidade de educação escolar, oferecida preferencialmente na rede regular de ensino, assegura aos alunos com deficiência, TGD e altas habilidades/superdotação serviços de apoio especializado no contexto da escolar e atendimento educacional "em classes, escolas ou serviços especializados, sempre que, em função das condições específicas dos alunos, não for possível a sua integração nas classes comuns de ensino regular". (BRASIL, 1996, art. 58, § 2). Desse modo, a Lei garante dois tipos de serviços: de apoio especializado, oferecidos na escola regular como complementares ou suplementares à classe comum e os denominados substitutivos (BRASIL, 1996), sendo ofertados por meio de classes, escolas ou serviços especializados. 
Nessa perspectiva, a LDB/96 (art. 60) reafirma o seu compromisso em oferecer essa modalidade de ensino a partir do apoio técnico e financeiro às instituições privadas sem fins lucrativos, ressaltando a relação contraditória entre Poder Público e privado na história da educação especial, na política educacional e no financiamento público. Desse modo, o Poder Público atua diretamente, tanto na oferta de serviços de educação especial, como no repasse de verbas a essas instituições, que podem conjugar várias fontes de receitas, públicas e/ou privadas, na prestação de seus serviços. Mas, ao mesmo tempo, o Estado assegura a ampliação do atendimento na rede regular de ensino, em classe comum, independentemente do apoio às instituições privadas, um compromisso inédito no âmbito da lei nacional brasileira sobre educação.

Nesse sentido, Garcia e Michels (2011, p. 114) salientam que se ao longo do século XX a educação especial foi estruturada em poucas instituições públicas e em rede paralela de instituições privadas, que desenvolveram o seu trabalho em regime de convênios e parcerias com as secretarias de educação de estados e municípios, no início do século XXI “a política de educação especial assume uma perspectiva inclusiva, estabelece uma relação mais definida com a educação básica e inicia um processo de proposições com a educação superior", no bojo do movimento de expansão do atendimento às pessoas com deficiência, TGD e altas habilidades/superdotação. É com base nessas considerações que analisamos a educação especial no contexto dos fundos destinados ao financiamento da educação, por meio da análise dos efeitos do Fundef e do Fundeb para o atendimento do público da educação especial no período de 2007 a 2013, no que tange ao número de matrículas no Brasil, e no Estado do Espírito Santo, e os valores mínimos por aluno da educação especial estabelecidos a nível nacional, e no Espírito Santo, para essa modalidade no âmbito desse fundo. Os dados sobre os censos escolares e financeiros sobre o Fundeb foram extraídos dos bancos de dados disponibilizados nas páginas eletrônicas do Ministério da Educação (MEC), do Instituto nacional de Estudos e Pesquisas Educacionais Anísio Teixeira (INEP) e do Fundo Nacional de Desenvolvimento da Educação (FNDE). Os dados referentes aos recursos recebidos do Fundeb foram consultados no Finbra.

\section{A educação especial no âmbito do Fundef e do Fundeb}

O Fundef foi instituído pela Emenda Constitucional $\mathrm{n}^{\circ}$ 14, de 12 de setembro de 1996 (EC/96) e regulamentado pela Lei 9.424, de 24 de dezembro desse 
mesmo ano, como fundo de natureza contábil ${ }^{2}$ em cada unidade da federação. Com esse mecanismo, $60 \%$ dos recursos dos impostos e transferências do Distrito Federal, estados e municípios foram direcionados ao ensino fundamental. O restante dos recursos manteve sua destinação às outras etapas e modalidades da educação básica, conforme a responsabilidade na oferta do Distrito Federal, estados e municípios, estabelecido no art. 211 da CF/88. (BRASIL, 1988).

A distribuição dos recursos do Fundef era proporcional ao número de alunos nas respectivas redes de ensino fundamental. (BRASIL, 1996). E sua normatização determinava que, no mínimo, $60 \%$ dos recursos do fundo deveriam ser aplicados ao pagamento dos professores do ensino fundamental em efetivo exercício do magistério e os $40 \%$ deveriam ser destinados na manutenção e desenvolvimento do ensino fundamental. (BRASIL, 1996). A EC/96 estabeleceu, ainda, a instituição de um valor mínimo, definido nacionalmente pelo governo federal, a ser aplicado por aluno em cada ano, cabendo a União complementar os fundos dos estados que não apresentassem condições de fazê-lo com recursos próprios. Esse desenho operacional era justificado para minimizar as desigualdades de condições de oferta do ensino fundamental nos estados brasileiros. Cabe destacar que o valor mínimo anual por aluno divulgado pelo governo federal, ao longo dos anos, foi questionado por pesquisadores da área de financiamento da educação, como Monlevade e Ferreira (1997). Os autores mostraram em seus estudos que o valor apresentado era inferior a média nacional, segundo os critérios de cálculo estabelecidos pela Lei ${ }^{\circ}$ 9.424/96. Desse modo, o governo federal deixava de cumprir o estabelecido na legislação.

Os impactos do Fundef foram analisados por diferentes autores (OLIVEIRA, 2007; MONLEVADE; FERREIRA, 1997) que ressaltaram os principais problemas e as consequências do referido fundo para a educação. Entre esses: a não destinação de novos recursos para a educação; a concentração de recursos no ensino fundamental; a utilização dos recursos do salário-educação pela União, para complementação dos fundos dos estados que não atingissem o valor mínimo nacional; e o não cumprimento dos dispositivos legais pelo governo federal do valor aluno-ano. Oliveira (2007) destaca que, embora não tenha significado um

2 Fundo criado no âmbito de cada estado e Distrito Federal, composto de $15 \%$ da arrecadação de quatro impostos e transferências constitucionais (FPE; FPM; Imposto sobre Operações relativas à Circulação de Mercadorias e sobre Prestação de Serviços de Transporte Interestadual e Intermunicipal e de Comunicação (ICMS); Imposto sobre Produtos Industrializados, proporcional às exportações (IPI-Exp); e Ressarcimento pela Desoneração de Exportações, de que trata a Lei Complementar n ${ }^{\circ} 87 / 1996$, denominada Lei Kandir. E tinha com a finalidade "redistribuir os seus recursos dentro do próprio Estado. Portanto, o efeito, dentro de um Estado, é o de retirar recursos de alguns municípios e os remeter para outros, de tal modo que uniformiza, em todo o Estado o valor aplicado por estudantes do ensino fundamental". (AMARAL, 2012, p. 132). 
aumento de recursos para a Manutenção e Desenvolvimento do Ensino (MDE), como previsto na $\mathrm{CF} / 88$, o Fundef trouxe a definição de mecanismos de distribuição de recursos, instituindo um novo padrão de gestão da educação básica.

No tocante à educação especial, especificamente em relação aos alunos matriculados no ensino fundamental, a legislação do Fundef prescreveu a definição de um valor mínimo por aluno-ano diferenciado do valor mínimo nacional, de acordo com o nível de ensino e o tipo de estabelecimento, que levasse em conta o custo por aluno. (BRASIL, 1996). Vale ressaltar que até 1999 não houve nenhum tipo de diferenciação de valores nos custos do Fundef; de 2000 a 2004 estipulou-se um acréscimo de $5 \%(1,05)$ para alunos de $5^{\text {a }}$ a $8^{\text {a }}$ séries e da educação especial, superior ao definido para o das séries iniciais urbanas do ensino fundamental $(1,00)$.

Em 2005 nova diferenciação elevou o fator de ponderação para 7\% $(1,07)$ para essa modalidade, com o Decreto $\mathrm{n}^{\circ} 5.374$, de 17 de fevereiro. (BRASIL, 2005). Assim, tendo como base o valor do fator de ponderação por aluno no ensino fundamental estabelecido para alunos da educação especial do ensino fundamental urbano e rural, o valor mínimo nacional garantido pela União em 2005 para a educação especial foi de $\mathrm{R} \$ 664,00$. A Lei $\mathrm{n}^{\circ}$ 9.424/96 estabelecia ainda que a distribuição de recursos do Fundef deveria considerar a diferenciação de custo por aluno, segundo os níveis de ensino e tipos de estabelecimento, adotando-se a metodologia de cálculo e as correspondentes ponderações. Observa-se, assim, o predomínio de uma lógica pragmática de financiamento em detrimento de uma racionalidade ético-política. (FARENZENA, 2006).

Viegas e Bassi (2009) observaram que no período de 1999 a 2006 houve uma expansão no número de matrículas de educação especial no ensino regular, em classe comum, e a atribuem ao fundo, por meio das diferenciações promovidas no valor aluno-ano em 2000 e, em 2005, a um fator decisivo no estímulo e expansão de matrícula no setor público, ainda que induzidas pela busca de recursos do Fundef. No cômputo das matrículas na educação básica, considerando as matrículas em escola exclusivamente especializadas ou em classes especiais de escolas regulares e em classes comuns, com e sem salas de recursos, nota-se um crescimento de $87 \%$ da oferta total. Os autores ainda destacam a existência de programas e recursos do FNDE e as iniciativas da Secretaria de Educação Especial (Seesp), que direcionaram fontes educacionais de recursos financeiros para essa modalidade de ensino. (VIEGAS; BASSI, 2009). Nesse sentido, apesar da melhoria na equiparação do valor nacional por aluno-ano no ensino público e das diferenciações feitas a partir de 2000, faz-se necessário atentar, como apontam Viegas e Bassi (2009), para os baixos valores anuais gastos por aluno, muito distantes de um custo-aluno condizente e suficiente. 
No ano de 2007 temos a implantação do Fundo de Manutenção e Desenvolvimento da Educação Básica e de Valorização dos Profissionais da Educação (Fundeb) criado pela Emenda Constitucional no 53, de 19 de dezembro de 2006 e regulamentado pela Lei $\mathrm{n}^{\circ} 11.494$, de 20 de junho de 2007 e pelo Decreto ${ }^{\circ}$ 6.253, de 13 de novembro de 2007, em substituição ao Fundef, que vigorou no período de 1998 a 2006. O Fundeb constitui um fundo especial, de natureza contábil, no âmbito estadual, e sua formação resulta da aplicação de percentuais, vinculados a receita arrecadada de impostos ${ }^{3}$ do Distrito Federal, estados e municípios, direcionados à educação por força do disposto no art. $212 \mathrm{da} \mathrm{CF} / 88$.

Ainda compõem o Fundeb, a título de complementação, uma parcela de recursos da União, sempre que, no âmbito do Estado, seu valor por aluno não alcançar o mínimo definido nacionalmente, em cada uma das etapas ou modalidades de ensino, fixado pelo poder executivo, de acordo com o inciso V, do art. $2^{\circ}$ da Emenda Constitucional $n^{\circ}$ 53/06. Essa participação foi estabelecida originalmente em $\mathrm{R} \$ 2$ bilhões para 2007, $\mathrm{R} \$ 3$ bilhões para 2008, $\mathrm{R} \$ 4,5$ milhões para 2009 e, a partir de 2010, em 10\% do valor total da contribuição do Distrito Federal, estados e municípios. Independentemente da origem, todo o recurso gerado é redistribuído para aplicação exclusiva na educação básica. O período de vigência estabelecido para o Fundeb foi de 2007 a 2020, sua implantação começou em $1^{\circ}$ de janeiro de 2007, sendo concluída em 2009, quando o total de alunos matriculados na rede pública foi considerado na distribuição dos recursos e o percentual de contribuição do Distrito Federal, estados e municípios para a formação do Fundo atingiu o patamar de $20 \%$.

O Fundeb garante que a maior parte dos recursos vinculados à educação seja aplicada à educação básica, por meio de seu mecanismo de distribuição de recursos com base no número de alunos das diversas etapas e modalidades, informado no censo escolar do ano anterior, sendo computados os estudantes matriculados nos respectivos âmbitos de atuação prioritária (art. 211, CF/88). Ou seja, os municípios recebem os recursos do Fundeb com base no número de alunos da educação infantil e do ensino fundamental e os estados com base nos alunos do ensino fundamental e médio. Na versão final do Fundeb foram

3 No Fundeb estão incluídos os impostos que já faziam parte do Fundef: Imposto sobre Circulação de Mercadorias e Serviços - ICMS, Fundo de Participação dos Municípios - FPM, Fundo de Participação dos Estados - FPE, Imposto sobre Produtos Industrializados, proporcional às exportações - IPI-exp e ressarcimento pela desoneração de Exportações de que trata a LC $n^{0}$ 87/96 (aumentados de 15\% para 20\%), acrescidos do Imposto sobre Propriedade de Veículos Automotores - IPVA, Imposto Territorial Rural - ITR e Imposto sobre Transmissão Causa Mortis e Doações - ITCMD, que foram gradativamente elevados em três anos até atingir $20 \%$ em 2009. Também compõem o Fundo as receitas da dívida ativa e de juros e multas incidentes sobre as fontes relacionadas. 
acrescentadas as matrículas de educação infantil e da educação especial da rede conveniada sem fins lucrativos. A distribuição de recursos também considera os fatores de ponderação que são definidos anualmente pela Comissão Intergovernamental de Financiamento para a Educação Básica de Qualidade, conforme previsto no inciso I, do art. 13 da lei 11. 494/2007. Assim, de acordo com Viegas e Bassi (2009), as etapas e modalidades são consideradas com pesos diferenciados na distribuição de recursos no novo desenho do financiamento da educação, situados em uma escala entre 0,7 a 1,3 pontos. Desse modo, a posição de cada especificidade nessa escala toma como referência o fator de ponderação de valor 1,0 definido para a matrícula das séries iniciais urbanas do ensino fundamental. O valor mínimo por aluno-ano da educação especial passa a receber um peso ponderado $20 \%$ superior ao valor por aluno de referência, em uma escala cujo valor mais elevado alcança $30 \%$. Os critérios utilizados na definição dos valores de ponderação, definidos pelo governo federal como parâmetro de distribuição de recursos, segundo Pinto (2007, p. 891), "esteve longe de ser o custo real dessas etapas e modalidades", uma vez que a decisão ficou restrita a negociações políticas entre estados e municípios e não apresentaram dados técnicos que justificassem ou explicitassem os fatores que levaram às diferenças entre os valores de ponderação.

No tocante à educação especial os valores de ponderação não sofreram alterações no período de 2007 a 2013, desde o início do Fundeb foi de 1,20, o que denota $20 \%$ maior que o padrão de referência. Cabe destacar que as matrículas das instituições do setor privado filantrópico conveniado ao poder público passaram a ser consideradas no Fundeb com o mesmo peso das do ensino público. Desse modo, segundo Bassi $(2012$, p. 5) "os fatores de ponderação paulatinamente asseguram receitas mais elevadas, o que ressaltou o aspecto indutor aos governos municipais e estaduais que mantinham ou que viessem a manter matrículas de educação especial".

Nesse contexto, observamos, ainda, políticas centralizadoras, por meio de programas e ações orientados pelo governo federal aos municípios que contribuíram, segundo Dourado (2007, p. 927), para a desarticulação de políticas direcionadas à educação básica no âmbito dos municípios e à adoção de projetos ligados às políticas do governo federal "em função da necessidade dos sistemas e escolas buscarem fontes complementares de recursos". Em contraposição, para Plestch (2012), ao longo do mandato do Presidente Luiz Inácio Lula da Silva (2003-2010) houve uma ampliação de investimentos financeiros voltados à garantia dos direitos das pessoas com deficiência, TGD, altas habilidades/superdotação, no contexto de implementação de políticas de inclusão social e educacional direcionados a diferentes grupos sociais. No caso 
da educação especial, as iniciativas se desenvolveram por meio de programas ${ }^{4}$, voltados à educação básica e ao ensino superior. E mudanças significativas na estrutura e funcionamento da educação especial, tendo em vista a elaboração de diretrizes para formulação de políticas públicas, entre as quais destacamos: a Política Nacional da Educação Especial na perspectiva da educação inclusiva - (PNEE-EI/08) - (BRASIL, 2008); o Decreto Presidencial de $n^{\circ} 7.611$, de 17 de novembro de 2011 (BRASIL, 2011) - e a Resolução no 4, de 2 de outubro de 2009. (BRASIL, 2009).

No intuito de garantir a implementação da PNEE-EI/08 (BRASIL, 1988), que tinha como expectativa a ampliação de recursos e serviços como apoio ao processo de escolarização dos alunos com deficiência, TGD e altas habilidades/ superdotação nas unidades de ensino, foi aprovado o Decreto Presidencial de $\mathrm{n}^{\mathrm{o}}$ 7.611/2011 (BRASIL, 2011) com a finalidade de garantir o compromisso da União na prestação de apoio técnico e financeiro aos sistemas públicos de ensino do Distrito Federal, estados e municípios, para o atendimento educacional especializado. A partir de 2010, os alunos com deficiência, TGD e altas habilidades/ superdotação passaram a ser contabilizados duplamente no âmbito do Fundeb, quando matriculados em classes comuns do ensino regular e pelo atendimento educacional especializado, podendo esse ser realizado na mesma escola que o aluno frequenta, em outra do seu entorno, ou por instituições comunitárias, confessionais ou filantrópicas sem fins lucrativos, que prestem esse tipo de serviço.

Diante desse cenário, concordamos com Garcia e Michels (2011, p. 116) quando afirmam que há um movimento claro de intervenção estatal na política educacional no que se refere à educação do público da educação especial, por meio "[...] da presença do Estado na criação de equipamentos públicos de educação especial", nas redes de ensino estaduais e municipais, embora as diretrizes da política nacional de educação especial assegurem que o atendimento educacional especializado possa ser realizado pelas instituições privadas sem fins lucrativos.

\section{A política do Fundeb e a oferta da educação especial no Brasil e no Espírito Santo}

A política do Fundeb e seus impactos, como incentivo financeiro para o esforço público de expansão de matrículas da educação especial no Brasil e no

4 Programa Educação Inclusiva: direito à diversidade; Programa Implantação de Salas de Recursos Multifuncionais; Programa Incluir; Programa Escola Acessível; e Programa Benefício da Prestação Continuada da Assistência Social - BPC na escola. 
Espírito Santo, podem ser verificados, inicialmente, no desempenho ascendente dos valores aluno/ano definidos pelo Fundeb para as matrículas da educação especial no período de 2007 a 2013 e aumento da diferença desse valor em relação ao das séries iniciais urbanas do ensino fundamental. Desse modo, os valores aluno/ano, nesse período, para a educação especial foram descritos no Gráfico 1, que foram obtidos multiplicando o valor do padrão de referência das séries iniciais do ensino fundamental pelo valor do fator de ponderação $(1,20)$.

GRÁFICO 1 - VALOR ALUNO/ANO DEFINIDO PELO FUNDEB - SÉRIES INICIAIS DO ENSINO FUNDAMENTAL URBANO E EDUCAÇÃO ESPECIAL NO BRASIL - 2007 A 2013 (R\$)

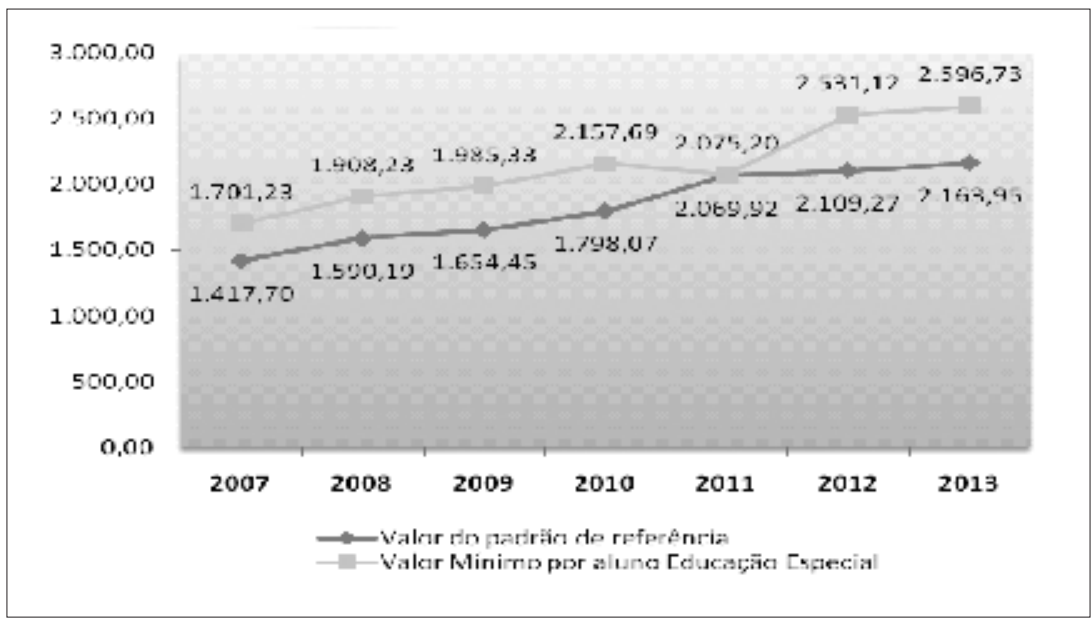

FONTE: MEC/FNDE.

Valores atualizados com base no INPC/IBGE de 12/2014.

Nesse período de vigência do Fundeb, evidenciamos diferenças entre o valor aluno/ano da educação especial em relação ao valor padrão das séries Iniciais do Ensino Fundamental urbano, haja vista o fator de ponderação de a educação especial ser $20 \%$ maior que o padrão de referência e as correções monetárias no decorrer da implantação do Fundeb. Assim, as matrículas de educação especial dos sistemas educacionais brasileiros contaram com valores crescentes de 2007 a 2013. Cabe destacar que em 2010, o mesmo valor aluno/ ano definido para as matrículas de educação especial passou a ser destinado às matrículas do atendimento educacional especializado implantado nos sistemas de ensino.

Observamos, ainda, um aumento de 53\% no valor aluno/ano da educação especial de 2007 a 2013, tendo em vista que no ano de 2007 o valor era de R\$ 
$1.701,23$ e foi elevado para 2.596,73 em 2013. Quando visualizamos o valor aluno/ano da educação especial no Estado do Espírito Santo, observamos também uma tendência crescente no período de 2007 a 2013, exceto no ano de 2009 que teve uma queda de $10 \%$, como podemos observar no Gráfico 2.

GRÁFICO 2 - VALOR ALUNO/ANO DEFINIDO PELO FUNDEB - SÉRIES INICIAIS DO ENSINO FUNDAMENTAL URBANO E EDUCAÇÃO ESPECIAL NO ESPÍRITO SANTO - 2007 A 2013 (R\$)

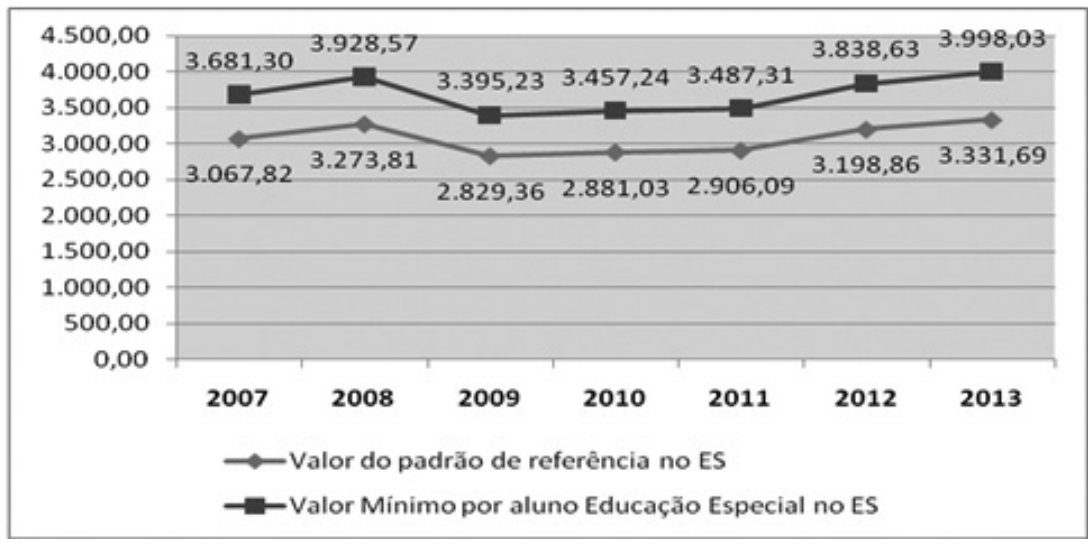

FONTE: MEC/FNDE.

Valores atualizados com base no INPC/IBGE de 12/2014.

Cumpre destacar que o valor aluno/ano tanto do padrão de referência como da educação especial do estado do Espírito Santo está acima do valor nacional, em decorrência não somente da elevação dos fatores de ponderação e do valor aluno/ano, mas também no cômputo progressivo das matrículas. O resultado financeiro dessa política de financiamento por aluno matriculado na educação especial pode ser observado na receita obtida pela rede estadual no Fundeb, que se mostrou crescente e contínua em decorrência das matrículas, de R $\$ 375$ milhões, em 2007, para R \$ 864 milhões, em 2013, como podemos observar no Gráfico 3.

O efeito da composição da política do fundo, principalmente, o aumento contínuo do valor aluno/ano da educação especial e dos programas tem repercutido na incorporação das matrículas da educação especial nos sistemas educacionais brasileiros, segundo os dados dos Censos Escolares de 2007 a 2013 a nível nacional e também no Estado do Espírito Santo. O número total de matrículas, no Brasil, atendidas em 2013, alcançou 843.342 ante 654.606 de 2007. Ao decompor o atendimento, conforme a classificação Escolas Especia- 
GRÁFICO 3 - RECEITA TRANSFERIDA DO FUNDEB PARA O ESTADO DO ESPÍRITO SANTO - 2007 A 2013

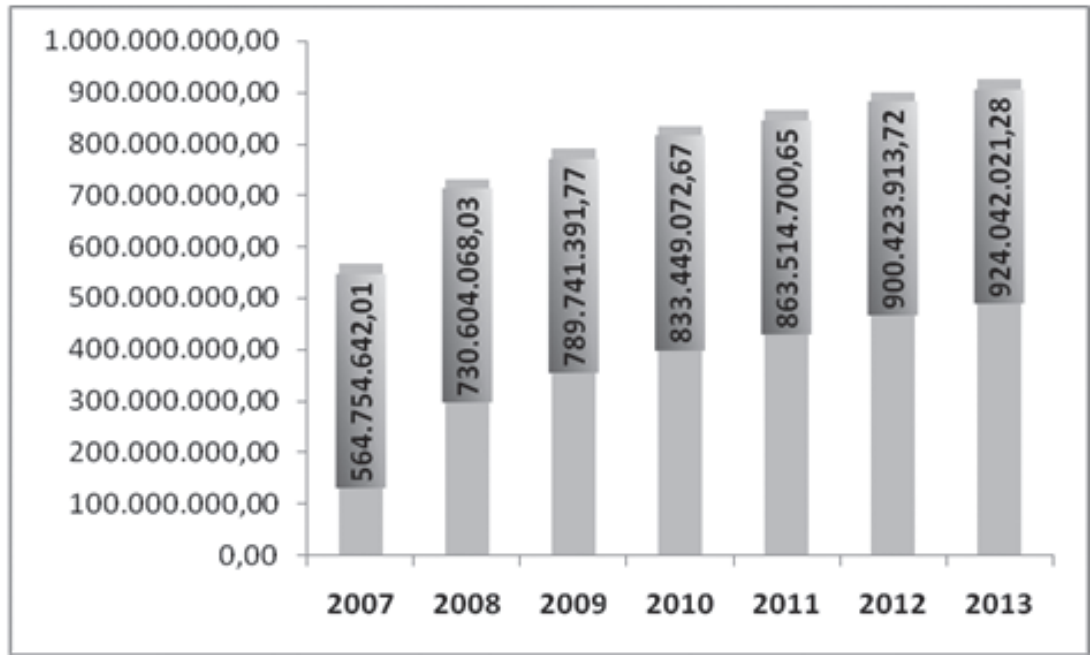

FONTE: Finbra.

Valores atualizados com base no INPC/IBGE de 12/2014.

lizadas e Classes Especiais e Escolas Regulares e Classes comuns observamos que $62,7 \%$ das matrículas de educação especial, em 2007, estavam nas escolas públicas, em 2013 esse número aumentou para 78,8\%. Em contraposição, as matrículas nas escolas privadas apresentaram um decréscimo de $37,3 \%$ em 2007 para 21,2\% em 2013, o que mostra que a política do Fundeb foi um das estratégias importantes para a ampliação do atendimento ao público da educação especial nos sistemas educacionais públicos brasileiros. No Estado do Espírito Santo, o desempenho de matrículas de educação especial apresentou oscilações significativas no período de 2007 a 2013. Evidenciamos que de 2007 a 2008 houve um crescimento aproximadamente de $28 \%$ no número de matrículas, de 15.886 para 20.346 respectivamente. Entretanto, nos anos seguintes observamos uma queda no número de matrículas para 16.057 em 2009 e 11.999 em 2010, retomando a tendência crescente a partir de 2010, como podemos observar no Gráfico 4.

Nesse movimento, a composição do atendimento alterou significamente ao longo do período, uma vez que a rede privada apresentou uma queda considerável no número de matrículas de educação especial de 8.674 em 2007 para 649 em 2013, ou seja, uma redução de aproximadamente 93\%, o que mostra uma expansão de atendimento pelos sistemas públicos para essa modalidade de 
GRÁFICO 4 - MATRÍCULAS DE EDUCAÇÃO ESPECIAL POR DEPENDÊNCIA ADMINISTRATIVA NO ESPÍRITO SANTO - 2007 A 2013

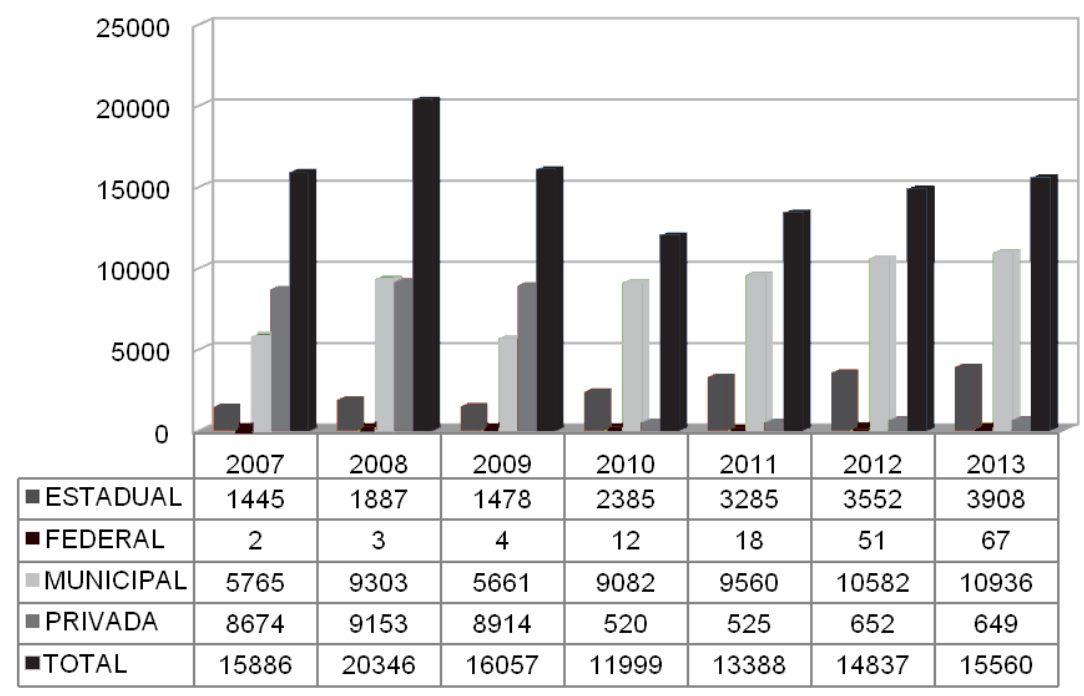

FONTE: Censo Escolar/Inep.

ensino, o que demonstra que a política de financiamento no âmbito dos fundos tem sido um fator importante para a ampliação do atendimento ao público da educação especial. Segundo o Inep, a acentuada redução no número de matrículas da rede privada decorre de ajustes na metodologia e no instrumento de coleta de dados cujo efeito alcançou todas as redes de ensino em nível nacional. Tais mudanças possibilitaram detalhar o registro do tipo de deficiência apresentada pelos alunos e impossibilitou a informação no censo daqueles com deficiência sem escolarização, ou seja, dos alunos que recebem atendimento educacional especializado exclusivamente nas instituições especializadas.

\section{Considerações finais}

Sendo assim, as políticas de financiamento e de educação especial, visando assegurar a inclusão escolar de alunos com deficiência, TGD e altas habilidades/ superdotação, desenvolvidas pelo governo federal, têm repercutido na incorporação das matrículas dessa modalidade de ensino nos sistemas educacionais brasileiros. Entretanto, a expansão de matrículas da educação especial nos sis- 
temas educacionais brasileiros não minimiza a ausência de condições mínimas de qualidade da rede pública de ensino para o atendimento a essa população que historicamente foi excluída do processo de escolarização.

Nessa direção, as políticas de educação especial na perspectiva inclusiva e a configuração do novo fundo, com a inclusão de todas as etapas e modalidades implicaram o incremento do número de matrículas do público da educação especial no Brasil e no estado do Espírito Santo e também o aumento de recursos para a educação especial, como podemos observar nos valores estimados para a modalidade de educação especial no âmbito do Fundeb. Entretanto, não podemos afirmar que as matrículas no cômputo do Fundeb produziram o efeito indutor esperado em termos de ampliação de recursos para essa modalidade no âmbito do estado pesquisado, tendo em vista que não se tem garantia de que esses recursos foram realmente investidos na modalidade a que se destinavam, considerando-se que a legislação do Fundeb permite aos entes administrativos certa flexibilidade no investimento dos recursos entre as diversas etapas e modalidades.

Assim, a educação especial pode ter recebido ou não as verbas repassadas de acordo com o número de matrículas. Desse modo, embora o Fundeb tenha contribuído para o aumento de verbas destinadas às etapas e modalidades da educação básica, o seu direcionamento continuou a depender fortemente das decisões, negociações e correlações de forças de interesse no âmbito do governo local, que define, em última instância, a destinação de recursos para as diferentes etapas da educação básica e modalidades de ensino no contexto de sua administração. (GOUVEIA; SILVA, 2012).

Cabe acrescentar ainda que essas verbas públicas podem ser destinadas às entidades privadas de educação especial, prevista na legislação do Fundeb, para oferecimento de serviços a essa população, refletindo as correlações de forças em torno dos recursos públicos no âmbito do Estado. Desse modo, os diferentes atores dentro de um processo permanente, regulado e negociado, no âmbito do Estado, determinam as distribuições, a alocação e a aplicação de recursos, bem como a publicização e a transparência de informações. Diante desse contexto, destacamos a necessidade de reformulações quanto ao controle social das verbas destinadas à educação especial no âmbito do Fundeb.

Nesse sentido, no que se refere à educação especial, faz-se ainda necessário ampliarmos a discussão acerca dos recursos financeiros voltados a essa modalidade de ensino, a (re)definição dos critérios de ponderação, a contagem de matrículas da rede privada de ensino para recebimento de recursos públicos, a articulação dos entes federados e, principalmente, o aumento da participação da União, na busca pela universalização do atendimento ao público da educação especial. 


\section{REFERÊNCIAS}

AMARAL, Nelson Cardoso. Para compreender o financiamento da educação básica no Brasil. Brasília: Líber Livro, 2012.

BASSI, Marcos Edgar. Financiamento da educação especial: política de fundos e inclusão em Santa Catarina. Poiesis - Revista do Programa de Pós-Graduação e Educação, Universidade do Sul de Santa Catarina, Unisul, Tubarão, v. 6, n. 10, p. 377-394, 2012.

BRASIL. Constituição (1988). Constituição [da] República Federativa do Brasil. Brasília: Senado Federal, 1988.

BRASIL. Lei de Diretrizes e Bases da Educação Nacional - LDB n.9.394, de 20 de dezembro de 1996. Diário Oficial [da] República Federativa do Brasil, Brasília, 23 dez. 1996.

BRASIL. Lei n. 9.424, de 24 de dezembro de 1996. Dispõe sobre o Fundo de Manutenção e Desenvolvimento do Ensino Fundamental e de Valorização do Magistério. Diário Oficial [da] República Federativa do Brasil, Brasília, 26 dez. 1996. Seção 1.

BRASIL. Emenda Constitucional n. 14, de 12 de setembro de 1996. Modifica os artigos 34, 208, 211 e 212 da Constituição Federal e da nova redação ao art. 60 do Ato das Disposições constitucionais Transitórias. Diário Oficial [da] República Federativa do Brasil, 13 set. 1996. Seção 1, p. 18109.

BRASIL. Decreto n. 5.374, de 17 de fevereiro de 2005. Fixa, para o exercício de 2005, o valor mínimo anual por aluno de que trata o art. $6^{\circ}, \S 1^{\circ}$, da Lei n. 9.424, de 24 de dezembro de 1996, e dá outras providências. Diário Oficial [da] República Federativa do Brasil, Brasília, 18 fev. 2005.

BRASIL. Lei n. 11.494, de 20 de junho de 2007. Regulamenta o Fundo de Manutenção e Desenvolvimento da Educação Básica e de Valorização dos Profissionais da Educação FUNDEB, de que trata o art. 60 do Ato das Disposições Constitucionais Transitórias; altera a Lei n. 10.195, de 14 de fevereiro de 2001; revoga dispositivos das Leis n. 9.424, de 24 de dezembro de 1996, 10.880, de 9 de junho de 2004, e 10.845, de 5 de março de 2004; e dá outras providências. Diário Oficial [da] República Federativa do Brasil, Brasília, 21 jun. 2007.

BRASIL. Decreto n. 6.253, de 13 de novembro de 2007. Dispõe sobre o Fundo de Manutenção e Desenvolvimento da Educação Básica e de Valorização dos Profissionais da Educação - FUNDEB, regulamenta a Lei no 11.494, de 20 de junho de 2007, e da outras providências. Diário Oficial [da] República Federativa do Brasil, Brasília, 14 nov. 2007. Seção 1, p. 18.

BRASIL. Política Nacional de Educação Especial na Perspectiva da Educação Inclusiva. Brasil: MEC/SEESP, 2008.

BRASIL. Conselho Nacional de Educação. Câmara de Educação Básica. Resolução CNE/CEB n. ${ }^{\circ} 4$, de 2 de outubro de 2009. Diretrizes operacionais para o atendimento educacional especializado na educação básica, modalidade educação especial. Diário Oficial [da] República Federativa do Brasil, 5 out. 2009. Seção 1, p. 17. 
BRASIL. Decreto n. 7.611, de 17 de novembro de 2011. Dispõe sobre a educação especial, o atendimento educacional especializado e dá outras providências. Brasília: Presidência da República, 2011. Diário Oficial [da] República Federativa do Brasil, Brasília, 18 nov. 2011. Seção 1, p. 12.

BUENO, Carmelita Cristina; KASSAR, Mônica de Carvalho Magalhães. Público e Privado: a educação especial na dança de possibilidades. In: ADRIÃO, Theresa; PERONI, Vera. O Público e o privado na educação: interfaces entre estado e sociedade. São Paulo: Xamã, 2005.

CURY, Carlos Roberto Jamil. Estado e políticas de financiamento em educação. Educação \& Sociedade, Campinas, v. 28, n. 100, p. 831-855, out. 2007.

DOURADO, Luiz Fernandes. Políticas e gestão da educação básica no Brasil: limites e perspectivas. Educação \& Sociedade, n. 100, p. 921-946, out. 2007.

FARENZENA, Nalú. A política de financiamento da educação básica: rumos da legislação brasileira. Porto Alegre, RS: UFRGS, 2006.

GARCIA, Rosalba Maria Cardoso; MICHELS, Maria Helena. A política de educação especial no Brasil (1991-2011): uma análise da produção do GT15 - educação especial na Anped. Revista Brasileira de Educação Especial, Marília, v. 17, p. 105-124, maio/ago. 2011.

GOUVEIA, Andrea Barbosa; SILVA, Isabelle Fiorelli. O gasto aluno-ano no Paraná (Brasil) e a situação de financiamento da educação nas regiões metropolitanas do Estado. Perspectiva, Florianópolis, v. 30, n. 1, p. 305-331, jan./abr. 2012.

KASSAR, Monica de Carvalho Magalhães. Percursos da constituição de uma política brasileira de educação especial inclusiva. Revista Brasileira de Educação Especial, Marília, v. 17, p. 41-58, maio/ago. 2011.

MAZZOTTA, Marcos José da Silveira. Educação Especial no Brasil: história e políticas públicas. 6. ed. São Paulo: Cortez, 2011.

MONLEVADE, João; FERREIRA, Eduardo Batista. O Fundef e seus pecados capitais: análise do Fundo, suas implicações positivas e negativas e estratégias de superação de seus limites. Ceilânida, Distrito Federal: Idea, 1997.

OLIVEIRA, Romualdo Portela de. O financiamento da educação. In: OLIVEIRA, Romualdo Portela de.; ADRIÃO, Theresa (Org.). Gestão Financiamento e direito à Educação: análise da Constituição Federal e da LDB. 3. ed. São Paulo: Xamã, 2007.

PINTO, José Marcelino de Rezende. A política recente de fundos para o financiamento da educação e seus efeitos no pacto federativo. Educação \& Sociedade, Campinas, v. 28, n. 100, p. 877-897, out. 2007.

VIEGAS, Luciane Torezan; BASSI, Marcos Edgar. A educação especial no âmbito da política de fundos no financiamento da educação. Reflexão e ação, v. 17, p. 54-87, 2009.

Texto recebido em 04 de agosto de 2015. Texto aprovado em 10 de novembro de 2015. 